\title{
VIDEO PROFIL SEBAGAI SARANA PROMOSI EFEKTIF DALAM MENUNJANG EKSISTENSI PROGRAM STUDI MANAJEMEN INFORMATIKA
}

\author{
Agus Aan Jiwa Permana ${ }^{1}$, Ni Ketut Kertiasih², I Putu Budhayasa ${ }^{3}$ \\ ${ }^{123}$ Program Studi Manajemen Informatika \\ Universitas Pendidikan Ganesha \\ Bali, Indonesia
}

e-mail : agus.aan@undiksha.ac.id ${ }^{1}$, ketut.kertiasih@undiksha.ac.id², budhayasa69@gmail.com³

\begin{abstract}
Abstrak
Video profil merupakan sebuah media elektronik untuk menyampaikan informasi yang sangat efektif dalam memperkenalkan suatu Prodi. Melalui media visual inilah maka semua informasi dapat dengan mudah dicerna oleh semua kalangan masyarakat. Prodi Manajemen Informatika adalah Prodi berada di Fakultas Teknik dan Kejuruan, Universitas Pendidikan Ganesha (Undiksha). Prodi ini, membutuhkan media promosi untuk sosialisasi kepada masyarakat untuk meningkatkan eksistensinya setelah melakukan perombakan kurikulum 2012 menjadi 2016. Berdasarkan hal tersebut, maka untuk melakukan promosi maka dikembangkan sebuah video profil Prodi Manajemen Informatika Undiksha. Dalam pembuatan video ini, digunakan Software Adobe Premiere Pro dan Adobe After Effects sehingga akan memudahkan pembuatan video profil. Dalam pembuatan Video Profil tahapan yang akan dibuat dimulai dari tahap Pra Produksi (Persiapan Ide, pengerjaan video, dan dialog atau Storyboard), Tahap Produksi (proses pengambilan gambar), Tahap Paska Produksi (Editing Video) serta elemen-elemen yang ada setiap tahapnya. Hasilnya berupa video profil yang digunakan untuk mempromosikan Prodi Manajemen Informatika.
\end{abstract}

Kata kunci: Video profil, Program Studi Manajemen Informatika, Promosi, Eksistensi Prodi

\begin{abstract}
A profile video is an electronic medium to convey highly effective information in introducing a Department. Through this visual media then all information can be easily digested by all circles of society. Department of Information Management is majoring in the Faculty of Engineering and Vocational, University of Education Ganesha (Undiksha). This department needs promotion media for socialization to the community to improve its existence after the reform of the 2012 curriculum to 2016. Based on this matter, then to do the promotion then developed a profile video Department of Information Management Undiksha. In making this video, used Adobe Premiere Pro Software and Adobe After Effects so it will facilitate the making of video profile. In the making of Video Profile stages that will be made starting from the Pre Production stage (Idea Preparation, video work, and dialogue or Storyboard), Production Stage (shooting process), Post-Production Stages and elements at each stage. The result is a profile video that is used to promote Information Management Program.
\end{abstract}

Keywords : Video profile, Study Program Information Management, Promotion, Existence Majors

\section{PENDAHULUAN}

Program Studi (Prodi) Manajemen Informatika adalah salah satu prodi vokasi yang berada di bawah Fakultas Teknik dan Kejuruan yang fokus di bidang Teknologi Informasi (TI). Mahasiswa lulusan Manajemen Informatika (MI) nantinya tidak hanya menjadi seorang pekerja, namun juga dapat menciptakan sebuah lapangan pekerjaan sendiri. Lulusan MI didukung dengan kemampuan berwirausaha akan menjadikan lulusannya mampu bersaing di dunia wirausaha. Hal ini dikuatkan oleh beberapa fakta bahwa lulusan MI saat lulus Jurnal Sains dan Teknologi | 238 
sudah menghasilkan suatu produk, seperti film kartun, media pembelajaran intraktif, dan web service.

Berdasarkan data Tabel 1 jumlah mahasiswa tiga tahun belakangan ini Prodi MI mengalami penurunan jumlah mahasiswa. Berdasarkan hasil survey yang dilakukan langsung di Prodi Ml pada 2 angkatan terakhir pada tahun 2014 sampai 2016 jumlah mahasiswa mengalami penurunan. Pada tahun 2014 jumlah penurunan mahasiswa sangat terlihat, terbukti dengan jumlah mahasiswa yang terdaftar sebanyak 41 orang, sedangkan tahun berikutnya (2015) kembali jumlah mahasiswa mengalami penurunan dengan jumlah mahasiswa menjadi 25 orang.

Tabel 1. Jumlah Mahasiswa Per Tahun (Sumber: Borang Akreditasi 2016 \& AMI)

\begin{tabular}{c|cc}
\hline No & Tahun & Jumlah (Orang) \\
\hline 1 & 2010 & 158 \\
2 & 2011 & 137 \\
3 & 2012 & 67 \\
4 & 2013 & 55 \\
5 & 2014 & 41 \\
6 & 2015 & 21 \\
7 & 2016 & 27 \\
8 & 2017 & 51 \\
\hline
\end{tabular}

Tahun 2016 dengan adanya media promosi berupa brosur dan promosi iklan di radio jumlah mahasiswa dapat meningkat sebanyak 27 orang. Dengan biaya promosi terbatas, promosi iklan melalui radio cukup mahal. Namun hal itu dapat dibantu dengan sumbangsih dari penyiar radio yang merupakan alumnus prodi MI. Terlebih dikeluarkannya kebijakan terkait penerimaan mahasiswa baru untuk jalur D3 hanya dapat dilakukan sekali saja yaitu melalui jalur SBMPTN (Seleksi Bersama Masuk Perguruan Tinggi Negeri) atau yang dikenal dengan Jalur Mandiri. Seleksi jalur ini hanya dilakukan pada akhir periode penerimaan mahasiswa baru.

Prubahan tren di masyarakat adalah banyak orang tua yang mengarahkan anaknya untuk masuk ke jalur sarjana (S1) karena beberapa alasan seperti gengsi dan kuliah D3 tanggung karena hanya tiga tahun.

Pada 2016 terjadi perubahan besar dimana Kurikulum 2012 yang sudah digunakan selama 17 tahun dirombak menjadi Kurikulum 2016. Kurikulum 2016 banyak mengalami perubahan dari kurikulum sebelumnya dan mengalami penyesuaian dengan kebutuhan dunia kerja karena melibatkan alumni dalam proses penyusunannya. Dengan keterbatasan dana untuk promosi, proses promosi perlu dibantu dengan media sosial untuk dapat promosi gratis. Generasi muda saat ini lebih suka untuk mengakses video melalui Youtube. Youtube adalah salah satu media promosi efektif saat ini sangat diminati oleh banyak orang dari segala golongan, usia dan jenis kelamin (Lampungsae, 2017). Jumlah pengguna Youtube sendiri mencapai total 1 miliar pengguna dengan masing-masing pengguna bisa menonton sekitar 1 jam video per harinya (Goodrow, 2017).

Berdasarkan permasalahan yang tengah dihadapi prodi, namun promosi agar dapat tetap jalan dan semakin meningkatkan minat dan jumlah mahasiswa prodi MI maka perlu dikembangkan sebuah video profil Prodi tentang Ml. Video ini akan mengulas visi misi, profil pengajar, fasilitas belajar, aktivitas pembelajaran dan kegiatan kemahasiswaan untuk meningkatkan eksistensi prodi $\mathrm{Ml}$ sehingga semakin populer di masyarakat luas dan khususnya untuk calon mahasiswa baru yang akan melanjutkan studi ke Prodi MI.

\section{LITERATUR}

\section{a. State Of The Art}

Menurut Goenawan, dkk (2013) dalam artikel yang berjudul "Perancangan Video Promosi Pulau Bawean Beserta Media Pendukungnya" yang ada di Jurnal DKV Adiwarna menjelaskan bahwa media promosi sangat berperan dalam memperkenalkan sebuah produk agar konsumen menginginkan produk tersebut.

Menurut (S. Jarwati, dkk. 2013) dalam artikel yang berjudul "Pembutan Video Profil Akademi Kebidanan Mitra Usadha Berbasis Multimedia" yang ada di jurnal Jurnal IJCSS menjelaskan bahwa Teknologi informasi 
berbasis multimedia di dalam bidang pemasaran sangat berperan penting, Video Profil merupakan media yang sering digunakan untuk mempromosikan semua bidang baik itu perusahaan, produk, hingga promosi untuk potensi daerah yang akan berguna bagi masyarakat dalam mencari informasi karena efektif dalam penggunaannya.

Dalam mempromosikan sekolah, (Kusuma, 2014) membuat sebuah company profil untuk SMK Muhammadiyah 1 Kepanjen dalam bentuk DVD sehingga mudah didistribusikan. Kemudian selain sekolah pembuatan video untuk promosi pariwisata juga dilakukan (Wicaksana and Purwanto, 2013) yang melakukan penelitian berjudul Pembuatan Video Profil Tempat Wisata Unggulan di Klaten Sebagai Media Promosi dan berhasil sebagai sebuah media promosi untuk berbagi informasi bagi para wisatawan.

\section{b. Prodi MI}

MI berdiri tanggal 15 Juli 1999, pada tahun 1999 sampai tahun 2001 Prodi MI berada di Fakultas Matematika dan IImu Pengetahuan Alam, pada 2001 Prodi MI Pindah ke Fakultas Teknik dan Kejuruan. MI memiliki Visi yaitu "Terwujudnya Prodi yang unggul dalam ilmu pengetahuan dan teknologi khususnya dalam bidang teknologi informasi sesuai dengan kebutuhan masyarakat lokal, nasional, maupun global yang berlandaskan falsafah Tri Hita Karana”. Untuk mewujudkan visi tersebut Prodi mempunyai 4 misi yaitu : " menyelenggarakan pendidikan yang efektif dalam bentuk layanan yang mampu memuaskan mahasiswa dibidang teknologi informasi untuk mendukung kemajuan dan pengembangan masyarakat yang memenuhi standar kelayakan, sesuai dengan keperluan pasar kerja berlandaskan Tri Hita Karana, Menyelenggarakan penelitian sebagai wujud pengembangan keilmuan dan keterampilan dibidang teknologi informasi berlandaskan Tri Hita Karana, Menyelenggarakan Pengabdian pada masyarakat sebagai implementasi dari hasil-hasil penelitian, pengkajian keilmuan, dan keterampilan di bidang teknologi informasi berlandaskan Tri Hita Karana,
Menyelenggarakan kerjasama bersama Stekehokder dalam rangka pengembangan dan peningkatan Prodi berlandaskan Trii Hita Karana".

Prodi MI memiliki susunan Struktur dari pimpinan Prodi, staf dosen, serta teknisi/laboran. Adapun struktur pimpinan di MI adalah Ketua Prodi, Sekretaris Prodi, dan Ketua Laboratorium. Sementara Staf dosen Prodi MI terdiri dari 11 dosen yaitu :

1. Prof.Dr. I Made Candiasa,M.I.Kom.

2. Ni Ketut Kertiasih, S.Si., M.Pd

3. Dr. Luh Joni Erawati Dewi,S.T., M.Pd

4. Dr.Komang Setemen,S.Si., M.T

5. Ni Wayan Marti S.Kom., M.Kom

6. Dr. Gede Rasben Dantes, S.T., M.T.I

7. K. Yota Ernanda A., S.Kom.,M.T., Ph.D

8. I Ketut Purnamawan,S.Kom., M.Kom

9. Putu Hendra Suputra,S.Kom., M.Cs

10. Agus Aan Jiwa Permana,S.Kom., M.Cs

11. A.A.G. Yudhi Paramartha,S.Kom., M.Kom

Mahasiswa Prodi MI Aktif dalam berbagai Ormawa yang ada di Universitas Pendidikan Ganesha, mulai dari Himpunan Mahasiswa MI (HMMI), Senat Mahasiswa Fakultas (SMF), Badan Eksekutif Mahasiswa (BEM), dan Majelis Permusyawaratan Mahasiswa (MPM). Terdapat beberapa ruangan yang ada di Ml seperti satu ruang untuk Ketua Prodi dan Sekretaris Prodi, satu ruangan untuk staf dosen dengan kapasitas 15 orang. Satu Ruang Ujian dan perpustakaan kecil yang digunakan untuk Ujian Tugas Akhir mahasiswa. Terdapat 1 Laboratorium Komputer, 1 Laboratorium Maintenance dan 1 Ruang Teori Umum yang digunakan untuk kuliah umum.

\section{c. Video Profile}

Menurut (Arsyad A, 2011) menyatakan bahwa video merupakan gabungan beberapa banyak frame yang diproyeksikan secara mekanis menggunakan media digital. Sedangkan menurut (Haryoko, 2012) Video Profil adalah media yang sangat efektif yang digunakan mempromosikan daerah, produk, dan mempromosikan suatu perusahaan tertentu.

Video profil atau istilah lainnya company profil merupakan solusi kreatif dan inovatif untuk berbagai kebetuhan, terutama untuk kebutuhan mempromosikan. Video profile 
adalah sebuah rekaman yang ditayangkan di media audio dalam bentuk visual lainnya, dimana digunakan untuk isi dari profil suatu instansi,daerah bahkan objek wisata.

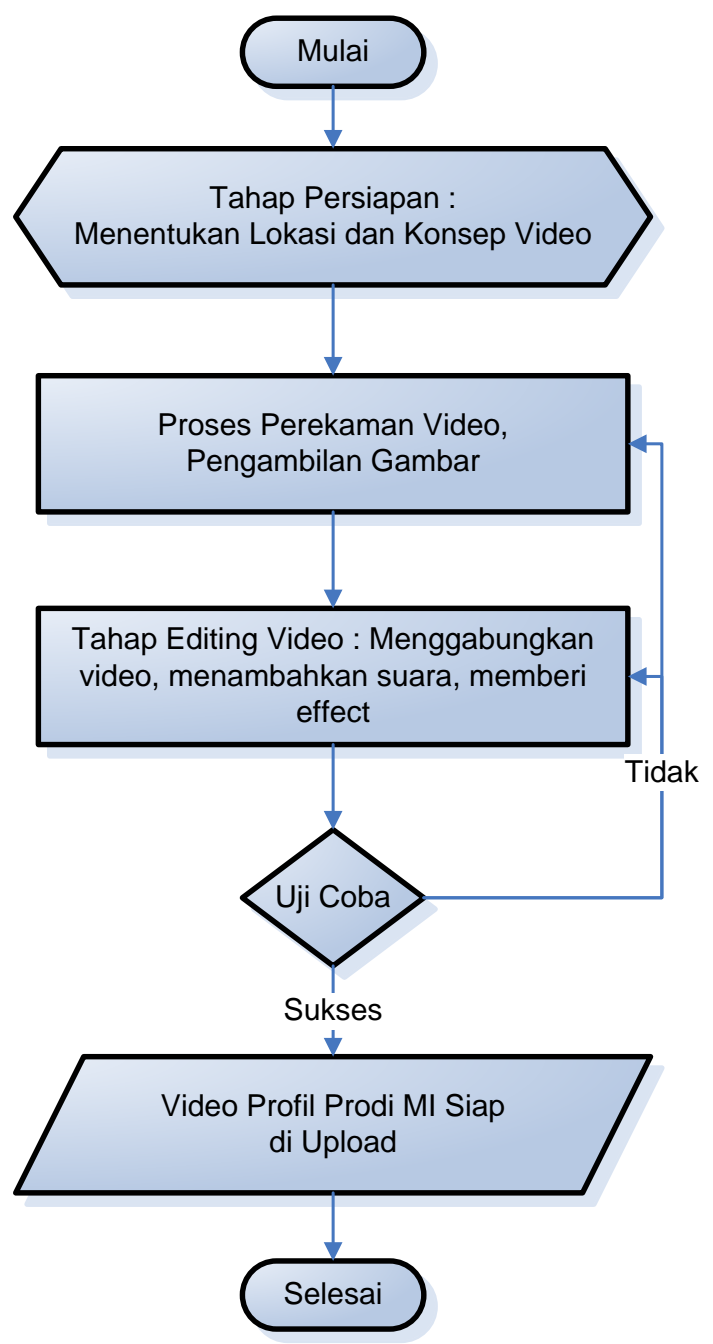

Gambar 1. Tahap Perencanaan Video

\section{d. Multimedia}

Menurut (Vaughan, 2005) Multimedia adalah beberapa kombinasi dari teks, gambar, suara, animasi dan video dikirim ke anda melalui komputer atau alat elektronik lainnya atau dengan manipulasi digital.

\section{e. Tahap Perencanaan Video}

Tahap perencanaan dalam pembuatan video profil $\mathrm{Ml}$ menggunakan Block Diagram. Block Diagram ini menjelaskan tentang tahapan-tahapan pembuatan Video Profil dari awal hingga selesai. Secara umum keseluruhan proses dari pembuatan Video Profil Ml dapat digambarkan dengan
Block Diagram seperti terlihat pada Gambar 1.

\section{f. Sosial Media Sebagai Media Promosi}

Pada era ini, generasi digital tidak dapat melepas smartphone dari tangannya.untuk mengakses sosial media (sosmed). Bukan hanya generasi muda saja yang terbius dengan gadget, namun anak-anak dan orang tua juga tidak ketinggalan. Pada era sosmed seperti saat ini yang didukung oleh kekuatan internet penting untuk mendukung keberhasilan promosi suatu usaha atau produk. Selain mudah dan cepat,sosmed menawarkan cara murah untuk berpromosi, bahkan bisa tanpa modal sama sekali. Terdapat beberapa sosmed yang marak digunakan sebagai media promosi untuk berbagi informasi seperti Facebook, Twitter, Instagram, Path, Kaskus, Google+, Market Place, Blog, Email , Youtube.

\section{METODE}

Dalam mengumpulkan data yang akan digunakan sebagai isi dalam video profil, dilakukan selama 6 bulan yang dimulai dari bulan November 2016 sampai April 2017 padai Fakultas Teknik dan Kejuruan Universitas Pendidikan Ganesha, dan langsung melakukan observasi di Prodi MI Undiksha.

Pengumpulan data secara observasi dilakukan dengan langsung datang ke kampus, Kemudian melakukan wawancara dengan Dosen Senior Bapak Prof. Dr I Made Candiasa sebagai pendiri MI. serta aawancara dengan staff dosen MI.

\section{HASIL DAN PEMBAHASAN}

Dalam proses proses pengembangan video menggunakan kerangka yang bernama Storyboard. Menurut (Effendy, 2002) Storyboard merupakan rekayasa adegan dalam sutu cerita dimana ceritanya akan dituangkan dalam gambar tangan atau komputer, dengan dilengkapi keterangan yang berisikan tulisan, waktu kejadian, musik yang dipakai dan durasi dari adegan yang diperlukan. storyboard dari video profil Prodi MI terdapat pada Table 2. 


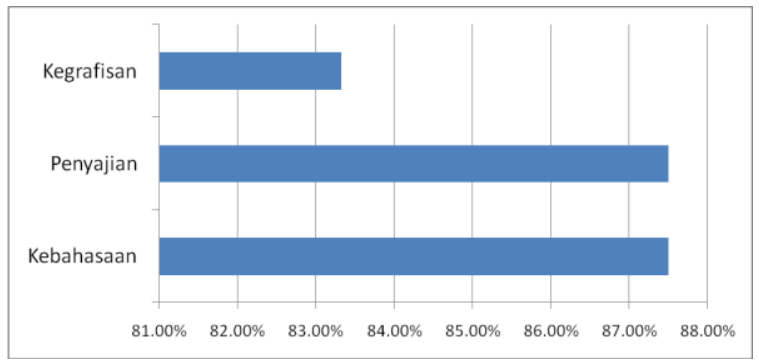

Gambar 2. Indikator Uji Media

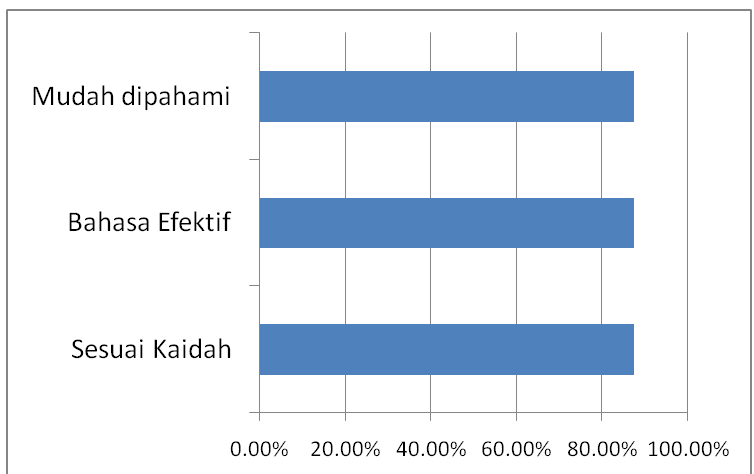

Gambar 3. Indikator Kebahasaan

Proses pengujian video profile telah dilakukan dengan menggunakan angket uji media yang dilakukan oleh 2 orang pakar. Secara garis besar uji ahli memiliki 3 indikator utama yaitu berdasarkan kebahasaan, penyajian, dan kegrafisan seperti Gambar 2. Kemudian hasil pengujian secara detail untuk kebahasaan dapat dilihat seperti Gambar 3.
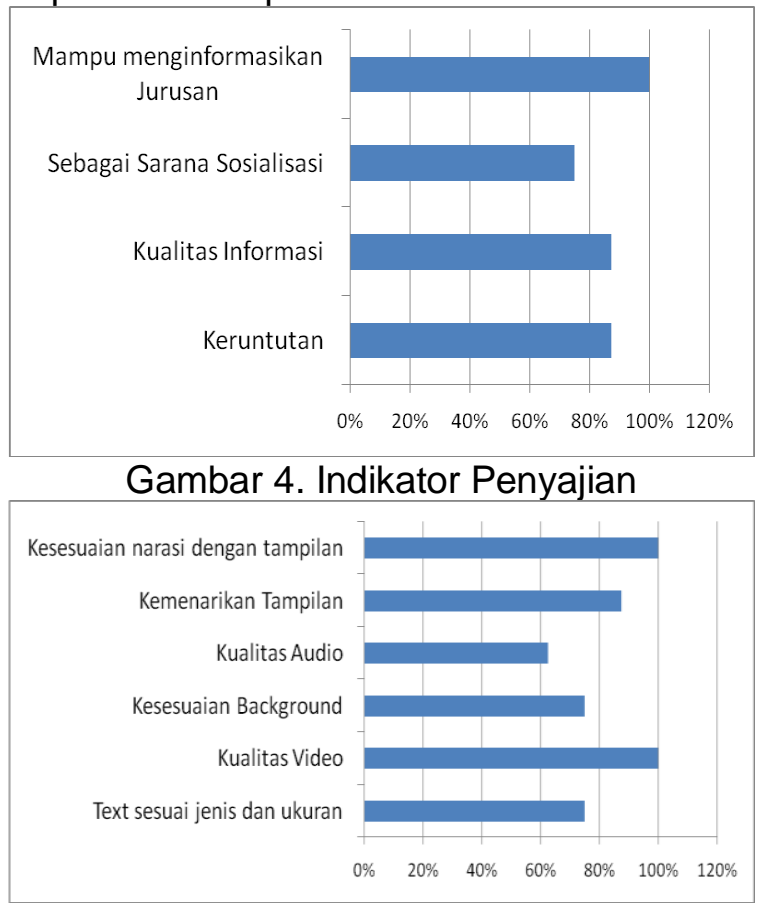

Gambar 5. Indikator Kegrafisan
Pada Gambar 4 ditampilkan hasil uji detail dari indikator penyajian, serta detail indikator kegrafisan pada Gambar 5. Dengan hasil rerata dari semua indikator adalah $\mathbf{8 5 . 5 8 \%}$ yang menyatakan video profile ini sudah sangat layak untuk dikembangkan menjadi media promosi jurusan.

Tabel 2. Storyboard Video Profil

\begin{tabular}{|c|c|}
\hline NO & DESKRIPSI \\
\hline 1 & $\begin{array}{l}\text { Narasi "Setelah Lulus Bingung } \\
\text { mau lanjut kemana?" }\end{array}$ \\
\hline 2 & $\begin{array}{l}\text { Narasi " Mari bergabung bersama } \\
\text { kami di Prodi D3 MI Undiksha ". }\end{array}$ \\
\hline 3 & $\begin{array}{l}\text { Narasi “ Prodi D3 Ml adalah salah } \\
\text { satu PRODI dibawah naungan } \\
\text { Fakultas Teknik dan Kejuruan } \\
\text { Universitas Pendidikan Ganesha “ }\end{array}$ \\
\hline 4 & $\begin{array}{l}\text { Menampilkan Ucapan selamat } \\
\text { datang di Kota Singaraja, yang } \\
\text { berlokasi di Desa Sangket, } \\
\text { Kecamatan Sukasada. } \\
\text { Suara music }\end{array}$ \\
\hline 5 & $\begin{array}{l}\text { Menampilkan Tugu Singa Ambara } \\
\text { Raja yang merupakan icon kota } \\
\text { Singaraja yang terletak di depan } \\
\text { Kantor Bupati Buleleng. } \\
\text { Suara Musik }\end{array}$ \\
\hline 6 & $\begin{array}{l}\text { Menampilkan Gedung rektorat } \\
\text { bagian depan Universitas } \\
\text { Pendidikan Ganesha } \\
\text { Suara Musik }\end{array}$ \\
\hline 7 & $\begin{array}{l}\text { Menampilkan Patung Ganesha } \\
\text { yang merupakan ikon Undiksha. } \\
\text { Suara Musik }\end{array}$ \\
\hline 8 & $\begin{array}{l}\text { Menampilkan Bagian depan } \\
\text { Fakultas Teknik dan Kejuruan } \\
\text { Suara Musik }\end{array}$ \\
\hline 9 & $\begin{array}{l}\text { Menampilkan halaman Fakultas } \\
\text { Teknik dan Kejuruan. } \\
\text { Suara Musik }\end{array}$ \\
\hline 10 & $\begin{array}{l}\text { Menampilkan Visi Prodi D3 MI } \\
\text { Suara Musik }\end{array}$ \\
\hline 11 & $\begin{array}{l}\text { Narasi “Visi, Terwujudnya Prodi } \\
\text { yang mampu mengembangkan } \\
\text { ilmu pengetahuan dan teknologi } \\
\text { khususnya dalam bidang teknologi } \\
\text { informasi serta menghasilkan } \\
\text { tenaga yang berkualitas dan } \\
\text { berdaya saing tinggi" }\end{array}$ \\
\hline 12 & Narasi “ Untuk mencapai Visi \\
\hline
\end{tabular}

Jurnal Sains dan Teknologi | 242 


\begin{tabular}{|c|c|}
\hline NO & DESKRIPSI \\
\hline & $\begin{array}{l}\text { tersebut Prodi D3 MI } \\
\text { melaksanakan } 3 \mathrm{MISI} \text { " }\end{array}$ \\
\hline 13 & $\begin{array}{l}\text { Menampilkan Misi Prodi D3 MI } \\
\text { Narasi }\end{array}$ \\
\hline 14 & $\begin{array}{l}\text { Menampilkan Profil Dosen Prodi } \\
\text { D3 MI. } \\
\text { Suara Musik }\end{array}$ \\
\hline 15 & $\begin{array}{l}\text { Menampilkan Profil Dosen Prodi } \\
\text { D3 MI. } \\
\text { Suara Musik }\end{array}$ \\
\hline 16 & $\begin{array}{l}\text { Menampilkan Profil Dosen Prodi } \\
\text { D3 Ml } \\
\text { Suara Musik }\end{array}$ \\
\hline 17 & $\begin{array}{l}\text { Menampilkan Profil Dosen Prodi } \\
\text { D3 MI } \\
\text { Suara Musik }\end{array}$ \\
\hline 18 & $\begin{array}{l}\text { Menampilkan Fasilitas Prodi D3 MI } \\
\text { Ruang Lab Komputer } \\
\text { Suara Musik }\end{array}$ \\
\hline 19 & $\begin{array}{l}\text { Menampilkan Fasilitas Prodi D3 MI } \\
\text { Ruang Lab Teori } \\
\text { Suara Musik }\end{array}$ \\
\hline 20 & $\begin{array}{l}\text { Menampilkan Fasilitas Prodi D3 MI } \\
\text { Ruang Kelas Teori } \\
\text { Suara Musik }\end{array}$ \\
\hline 21 & $\begin{array}{l}\text { Menampilkan Fasilitas Prodi D3 MI } \\
\text { Ruang Lab Jaringan atau Ruang } \\
\text { Perpustakaan mini dan Ruang } \\
\text { Ujian } \\
\text { Suara Musik }\end{array}$ \\
\hline 22 & $\begin{array}{l}\text { Menampilkan Sistem pembelajaran } \\
\text { di Prodi D3 MI. } \\
\text { Suara Musik }\end{array}$ \\
\hline 23 & $\begin{array}{l}\text { Menampilkan Kegiatan } \\
\text { Kemahasiswaan } \\
\text { Gema Informatika (Gl) } \\
\text { Suara Musik }\end{array}$ \\
\hline 24 & $\begin{array}{l}\text { Menampilkan Kegiatan } \\
\text { Kemahasiswaan } \\
\text { Pekan Kegiatan Mahasiswa } \\
\text { Informatika (PKMI) } \\
\text { Suara Musik }\end{array}$ \\
\hline 25 & $\begin{array}{l}\text { Menampilkan Kegiatan } \\
\text { kemahasiswaan } \\
\text { Malam Gelar Informatika (MGI) } \\
\text { Suara Musik }\end{array}$ \\
\hline 26 & $\begin{array}{l}\text { Menampilan Kegiatan } \\
\text { Kemahasiswaan } \\
\text { Seminar Kewirausahaan } \\
\text { Suara Musik }\end{array}$ \\
\hline 27 & Narasi “ Visi + Misi “ \\
\hline
\end{tabular}

\begin{tabular}{ll}
\hline NO & \multicolumn{1}{c}{ DESKRIPSI } \\
\hline 28 & Narasi “Menghasilkan Lulusan \\
& yang berkompeten" \\
29 & $\begin{array}{l}\text { Penutup } \\
\text { Suara Musik }\end{array}$ \\
\hline
\end{tabular}

Video profile prodi MI sudah berhasil diimplementasikan sesuai dengan urutan storyboad. Adapun beberapa hasil implementasi untuk pembukaan dapat ditampilkan seperti Gambar 6. Kemudian terkait dengan konten dapat dilihat seperti pada Gambar 7-12 dan Gambar 13 untuk penutup.

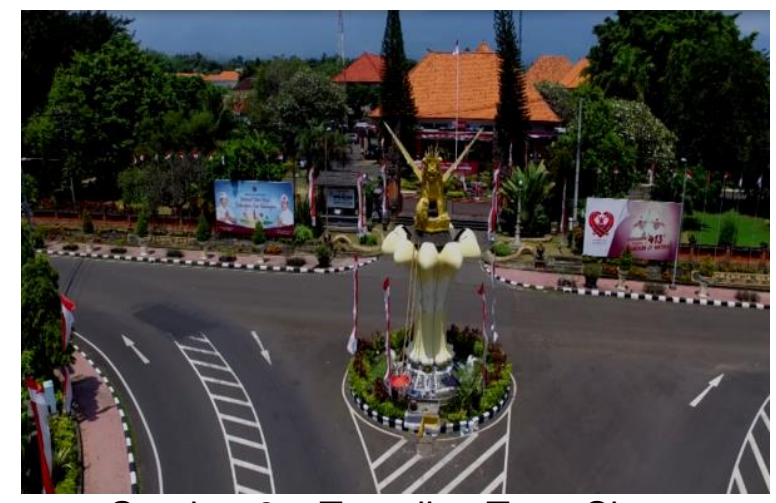

Gambar 6a. Tampilan Tugu Singa

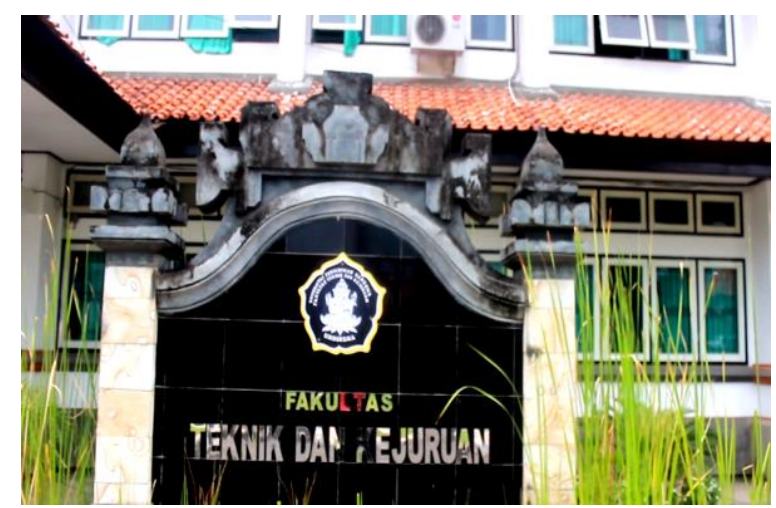

Gambar 6b. Tampilan FTK Undiksha

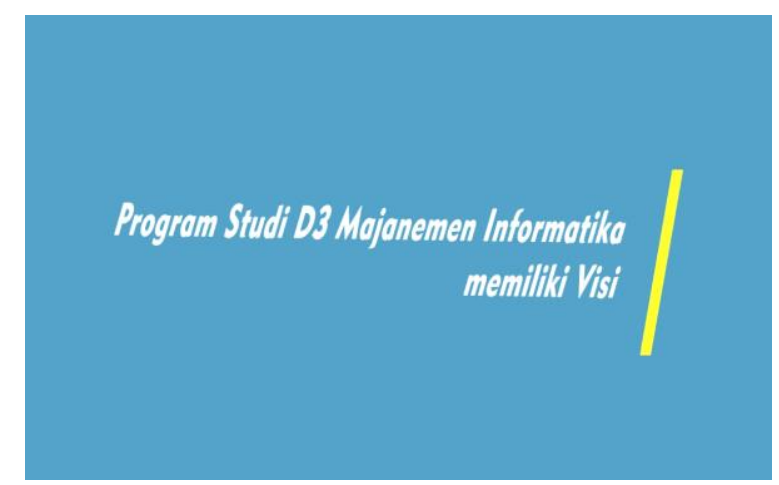

Gambar 7. Tampilan Awal Visi Misi Jurnal Sains dan Teknologi | 243 


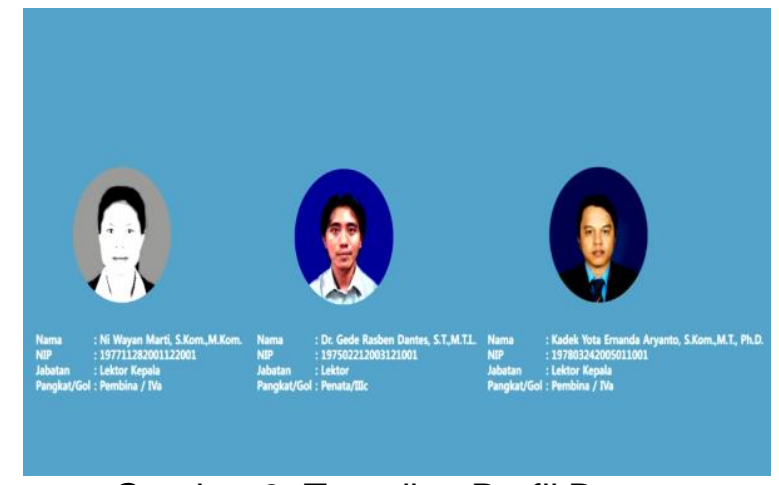

Gambar 8. Tampilan Profil Dosen

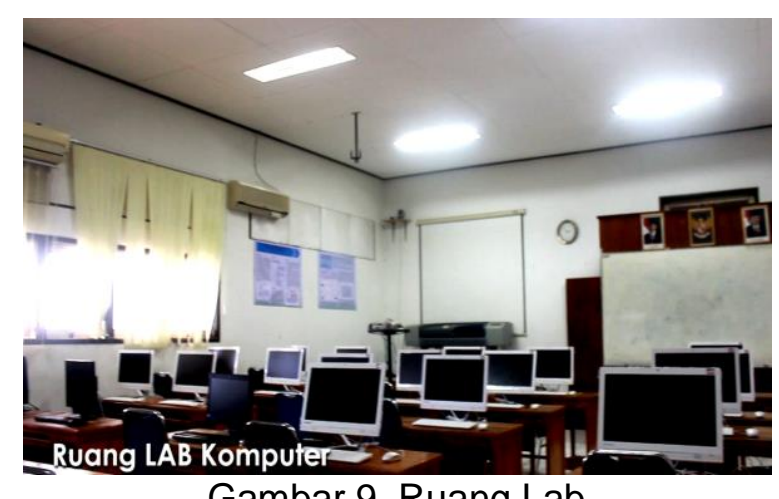

Gambar 9. Ruang Lab

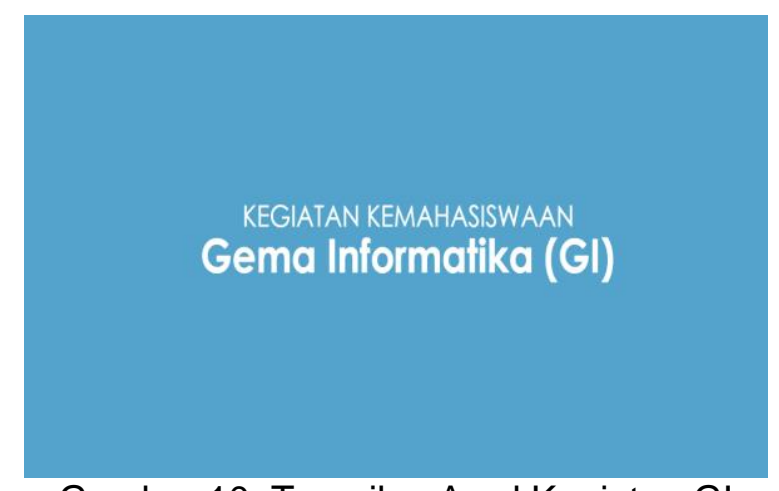

Gambar 10. Tampilan Awal Kegiatan GI

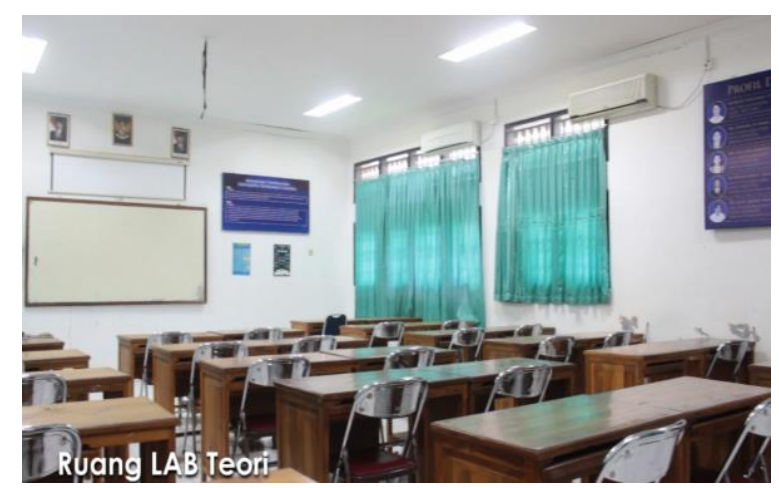

Gambar 11. Lab Teori

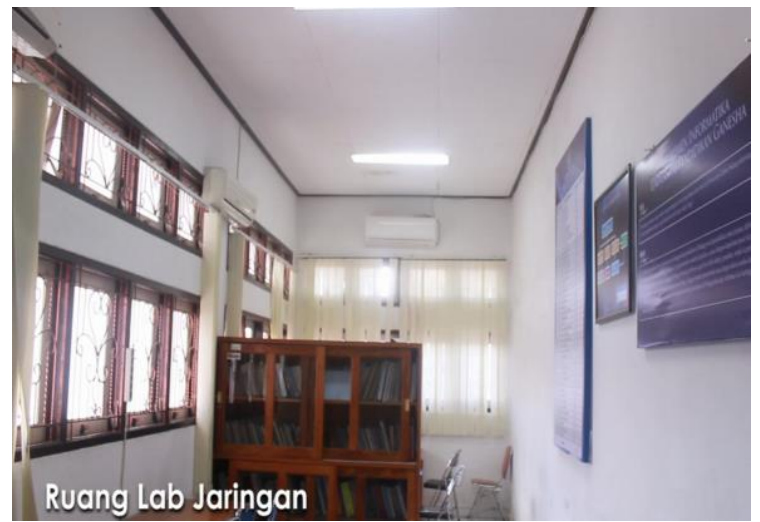

Gambar 12. Lab Jaringan

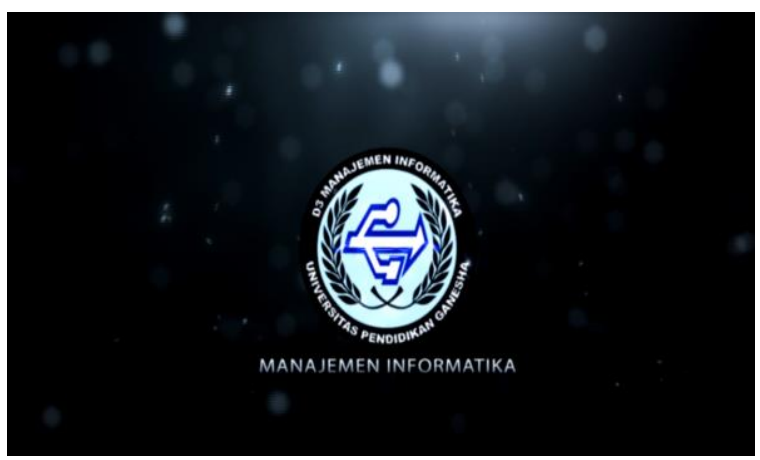

Gambar 13. Bagian Penutup

\section{Implementasi Proyek}

Implementasi video adalah berdasarkan storyboard. Proses pembuatan video sudah masuk ke tahap produksi. Terdapat beberapa proses dan tools yang digunakan dalam pembuatan video. Proses tersebut antara lain penyuntingan dilakukan menggunakan Software Adobe Premiere Pro dan untuk penambahan efek animasi, menggunkan Adobe After Effect. Secara detail proses pengembangan video akan dijelaskan seperti berikut.

\section{a. Proses Penyuntingan Video}

Pada proses editing video yang akan dibuat, terlebihdahulu membuat New Project pada Adobe Premiere untuk 69 memudahkan pembuatan video pada project baru sesuai dengan apa yang diinginkan, seperti pada Gambar 14. 


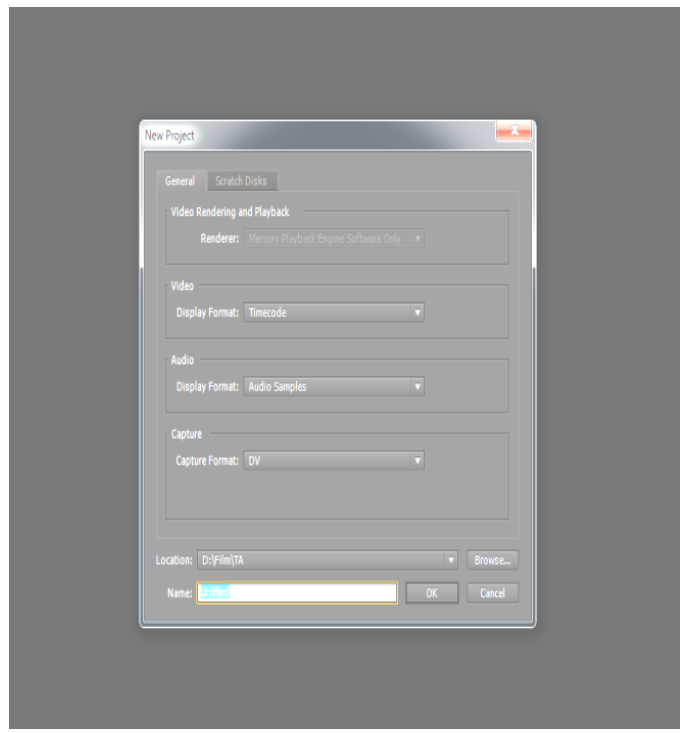

Gambar 14. Membuat Proyek Baru

\section{b. Mengimport Video}

Pada menubar di Adobe Primer Pro, pilih menu file lalu import, kemudian akan tampil kotak dialog import seperti Gambar 14. Pilih file video yang diinginkan dan klik tombol Open, maka file tersebut akan muncul di dalam halaman Project Window) untuk dimanipulasi sesuai keinginan, seperti Gambar 15.

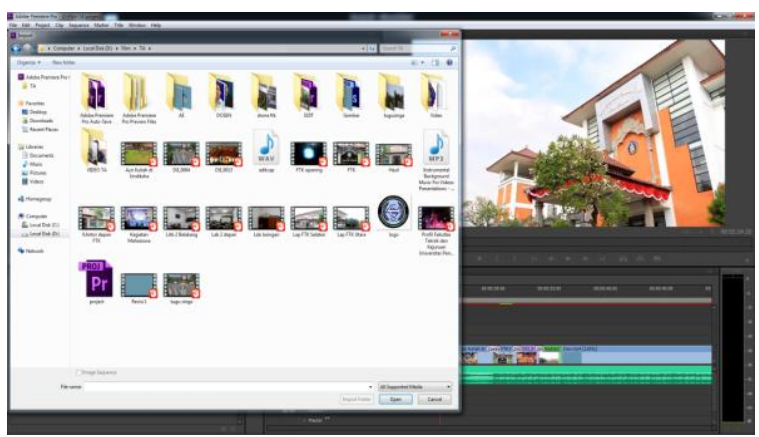

Gambar 15. Mengimport Video

\section{c. Memotong Klip Video}

Pada tahap ini dilakukan dengan cara Pilih Video yang akan dipotong, lalu Klik Rasor Tool pada toolbox, lalu Klik video untuk menentukan durasi video yang ingin dipotong, setelah terpilih tekan tombol delete seperti pada Gambar 16.

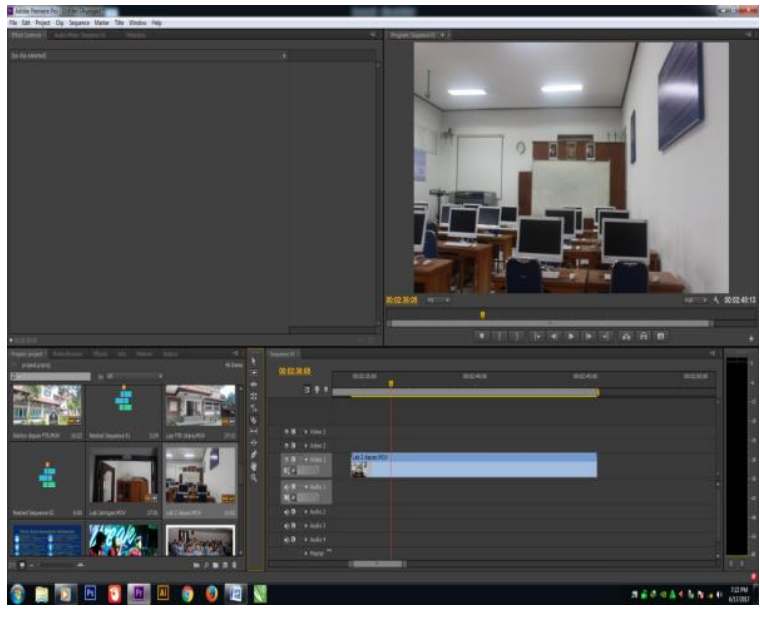

Gambar 16. Proses Potong Video

\section{d. Memberikan Efek Transisi Pada Video}

Efek transisi adalah efek animasi video untuk pada saat perpindahan dari satu video ke video lain sehingga video menjadi lebih menarik. Caranya adalah dengan mencari efek transisi yang diinginkan di bagian jendela Effects > Video Transitions, lalu lakukan drag and drop efek yang diinginkan dan letakkan di awal maupun di akhir klip seperti pada Gambar 17.

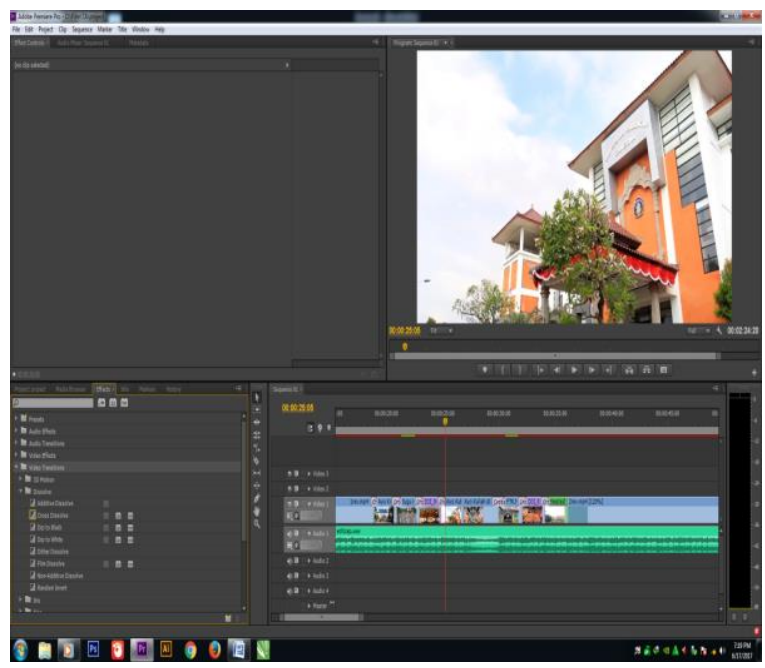

Gambar 17. Memberikan Effect

\section{e. Export Video}

Setelah semua video telah disusun dan diberikan efek animasi yang sesuai, maka masuklah pada proses akhir yaitu rendering, dimana semua klip dan animasi akan disatukan menjadi sebuah video yang utuh, sehingga video dapat diputar Jurnal Sains dan Teknologi | 245 
dimanapun tanpa harus melalui Adobe Premiere lagi. Caranya adalah dengan memilih menu file > Export > Media, kemudian lakukan pengaturan (setting) pada kotak dialog export setting sesuai yang diinginkan. Detail proses ini dapat dilihat seperti pada Gambar 18.

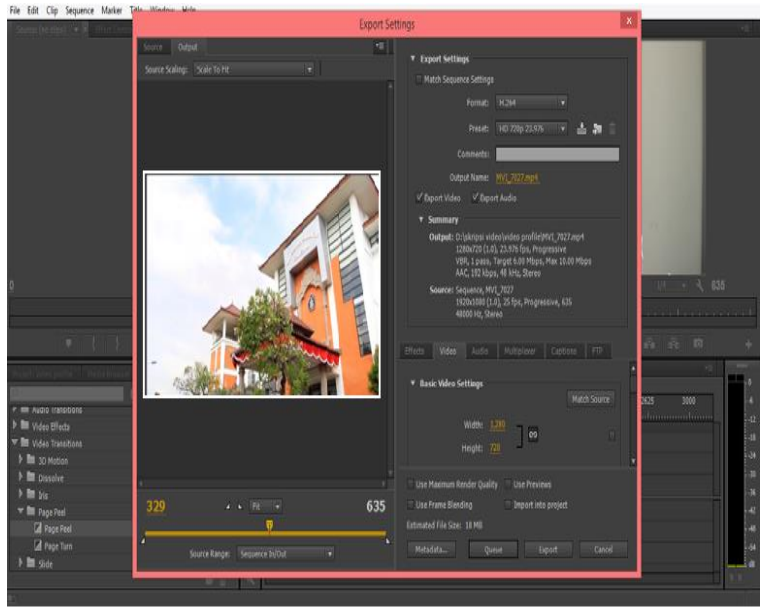

Gambar 18. Export Video

\section{f. Hasil Video}

Sesuai dengan proses yang telah dilakukan, yaitu dengan dibuatnya video profil Jurusan D3 Manajemen Informatika, sebagai sarana media promosi untuk mensosialisasikan Jurusan D3 Manajemen Informatika Undiksha agar lebih mudah dikenal oleh masyarakat umum.

Video ini dapat diunggah (upload) ke media sosial seperti Youtube untuk dipublikasikan ke dalam dunia maya. Video profil Jurusan D3 Manajemen Informatika ini dikelompokkan atas tiga tampilan, yaitu tampilan pembuka (Gambar 19), tampilan isi seperti (Gambar 7-12) dan, dan tampilan penutup (Gambar 13).

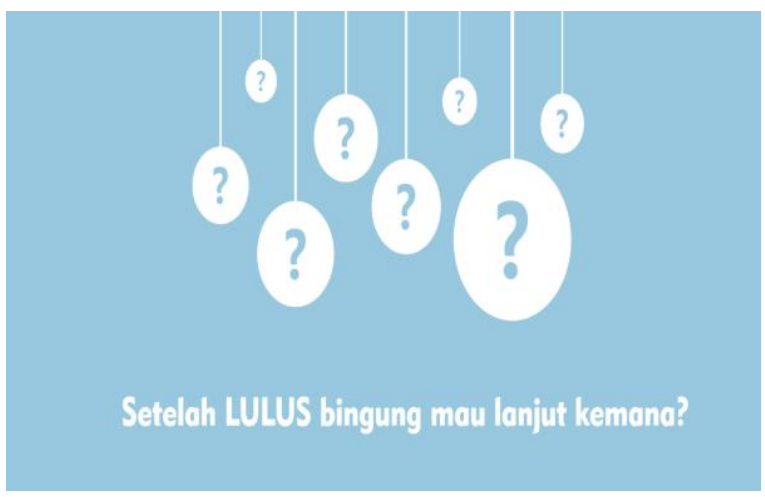

Gambar 19.a Tampilan Pembuka

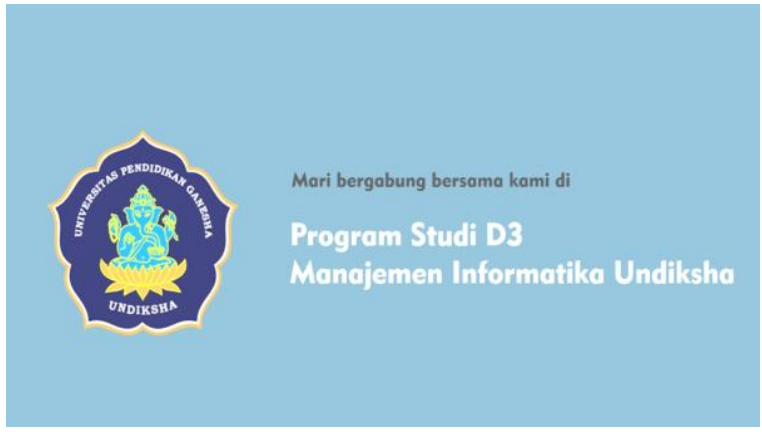

Gambar 19.b Tampilan Pembuka

\section{KESIMPULAN}

Video profil telah mampu untuk diimplementasikan dengan baik dan melalui proses uji coba dan uji media terkait video profile. Hasilnya, video profile yang dikembangkan layak untuk menjadi media promosi prodi $\mathrm{MI}$ dengan menampilkan informasi terkait dengan Prodi Ml yang ditampilkan dalam waktu singkat selama tiga menit "Three Minute Video". Hal ini sengaja diperhitungkan supaya penonton tidak merasa bosan. Apabila video ini diunggah ke Youtube sebagai salah satu media promosi yang efektif untuk saat ini maka akan banyak ditonton oleh siswa, orang tua, dan alumni sehingga lebih mudah mempromosikan prodi. Proses promosi dapat efektif karena keterbatasan dana yang dimiliki prodi untuk melakukan promosi ke sekolah-sekolah yang berasal dari fakultas. Dengan adanya video ini, proses promosi lebih mudah lagi karena dapat menyimpan video prodi ke dalam DVD kemudian mengirimkannya ke sekolah-sekolah baik SMA maupun SMK terutama yang berada di luar Singaraja.

\section{UCAPAN TERIMAKASIH}

Ucapan terimakasih ditujukan para Mahasiswa Info Angkatan 2014 yang sudah meluangkan waktunya untuk membantu proses pembuatan video profile. Kemudian kepada seluruh pegawai dan staff dosen MI serta pegawai dan staff di lingkungan Fakultas Teknik dan Kejuruan, Undiksha yang telah banyak memberikan dukungan sehingga video profile ini dapat diselesaikan. 


\section{DAFT AR PUSTAKA}

Arsyad A (2011) 'Media Pembelajaran', in . Jakarta: Rajawalli Pers, p. 49.

Effendy, H. (2002) Mari Membuat Film panduan menjadi produser. Jakarta: Konfiden.

Goodrow, C. (2017) 'Pengguna YouTube Tonton 1 Miliar Jam Video Sehari', pp. 3-7. Available at: www.kompas.com.

Haryoko, T. (2012) Pembuatan Video Company Profile Rumah Sakit Amal Sehat Wonogiri. Universitas Surakarta.

Kusuma, F. S. (2014) 'Kepanjen, Perancangan Company Profile Berbasis Video Sebagai Media Promosi SMK Muhammadiyah 1', in. Universitas Negeri Malang. Available at: http://jurnal-
online.um.ac.id/data/artikel/artikel4869B C67FD9FD14647441F5AF348E025.pdf

Lampungsae (2017) 'Inilah 10 Media Sosial Paling Efektif untuk Promosi Bisnis dan Produk', pp. 2-5. Available at: www.Lampungsae.com.

S. Jarwati, B. and K. (2013) 'Pembuatan Video Profil Akademi Kebidanan Mitra Usada Berbasis Multimedia', Jurnal IJCSS.

Vaughan, R. (2005) 'Multimedia: What it is and What it can do for our Students', $p$. 2005. Available at: http://jaltcall.org/cjo/5_00/vaughan. html.

Wicaksana, R. B. S. and Purwanto, A. (2013) 'Pembuatan Video Profil Tempat Wisata Unggulan di Klaten', 14(4), pp. 37-39. 